\title{
An evaluation of general professional training for dentistry in Scotland
}

\author{
L. Plowman, ${ }^{1}$ K. Musselbrook ${ }^{2}$
}

\begin{abstract}
The first General Professional Training (GPT) scheme in Scotland ran from August 1996 to July 1998 with sixteen trainees completing one year in general practice and two six-month blocks in the hospital and community services. An independent evaluation of the scheme focussed on the advantages and disadvantages of GPT and the level of support for the scheme as well as providing stakeholders with an opportunity to contribute to its development. This paper reports the findings of the evaluation.
\end{abstract}

G eneral Professional Training is 'the structured further development of knowledge, skills and attitudes common to all branches of the dental profession which will provide a basis for informed career choice and improved patient care.' ${ }^{1}$ It is designed to meet the need for dentists to have experience in primary and secondary care, to facilitate better communication between the different branches of the profession and to provide a more flexible and effective service.

There have been calls for a two-year period of postgraduate training for dentists for nearly two decades ${ }^{2}$ and in 1995 the Chief Dental Officer's Report ${ }^{3}$ recommended setting up pilot schemes to 'test the feasibility of introducing a two year period of General Professional Training. This recommendation was strengthened in a 1996 White Paper ${ }^{4}$ which stated that 'the Government intends to support the development of General Professional Training in the NHS, ideally for all dentists after graduation'. As a consequence, a number of differently organised GPT schemes have been introduced in the UK to inform the devel-

\footnotetext{
${ }^{1}$ Scottish Coucil for Reasearch in Education, 15, St John Street, Edinburgh EH8 8JR

2 Teaching and Learning Service, University of Glasgow, 69 Oakfield Avenue, Glasgow, G12 8LW. REFEREED PAPER

Received 01.04.99; accepted 21.07.99

(C) British Dental Journal 2000; 188: 154-159
}

opment of a two-year period of training for all dental graduates.

The GPT programme in the North East and East of Scotland was one of a number of such schemes and ran from August 1996 to July 1998. The Scottish Council for Research in Education was commissioned by the Scottish Council for Postgraduate Medical and Dental Education (SCPMDE) to conduct an independent evaluation of this first GPT scheme in Scotland. The following account is based on the report of that evaluation. ${ }^{5}$

The pilot scheme and its evaluation The North East and East of Scotland GPT scheme was managed by the Regional General Practice Vocational Training Adviser and was supported by a steering group. The pilot scheme involved 16 trainees (GPTs) completing one year in general practice and two six-month blocks in the hospital and community services, following one of the paths represented in Figure 1. The trainees were required to attend eight GPT core days over the two years as well as attending study days with trainees in standard general practice, community and hospital training posts. The general practice and community service posts were distributed throughout the region but the hospital posts were created from the senior house officer ( $\mathrm{SHO}$ ) establishment of a university dental hospital and school.

\section{In brief}

- In this General Professional Training pilot scheme dentists spend time in general practice as well as the hospital and community services.

- The scheme encouraged greater understanding of each branch of the profession for both trainers and trainees and provided more opportunities to develop a range of clinical and generic skills than the established training schemes.

- This evaluation provides guidance for the development of future schemes.

The pilot was funded by SCPMDE from within existing resources and all vocational training and SHO posts were part of the training grade establishment. Due to a shortage of training posts in the community dental service (CDS), four posts were made available by SCPMDE for the duration of the pilot. Without this, no consideration of the role of the CDS would have been possible.

The aims of the evaluation were:

- to highlight the advantages and disadvantages of GPT and the strengths and limitations of the model contrasted with the standard programmes

- to identify the challenges facing GPT and make recommendations for improvement if appropriate

- to gauge the level of interest and support for the expansion of GPT from young dental graduates and from trainers in each branch of the service and to provide them with the opportunity to contribute towards the development of the pilot.

\section{The evaluation}

All trainees were surveyed twice. Questionnaires were sent to 150 trainees at Stage 1 , the start of the training period, to establish their expectations of the chosen training programme. In addition to the 16 GPTs, 


\section{EDUCATION general professional training}

Fig. 1 Structure of the pilot scheme

this figure included all Scottish trainees in the established general practice, community and hospital schemes. The same number of trainees were questioned at Stage 2, towards the end of the programme, so that comparisons could be made between expectations and actual experiences for trainees on the established schemes and those on the GPT pilot.

In addition, 124 trainers from GPT and the established schemes were surveyed at Stage 2 so that trainees' and trainers' perceptions could be compared. Response rates to questionnaires at Stages 1 and 2 were good at $67 \%$ for Stage 1 and $76 \%$ for Stage 2 (Table 1). Quantitative data was analysed using SPSS (Statistical Package for the Social Sciences) software.

The evaluation also included qualitative

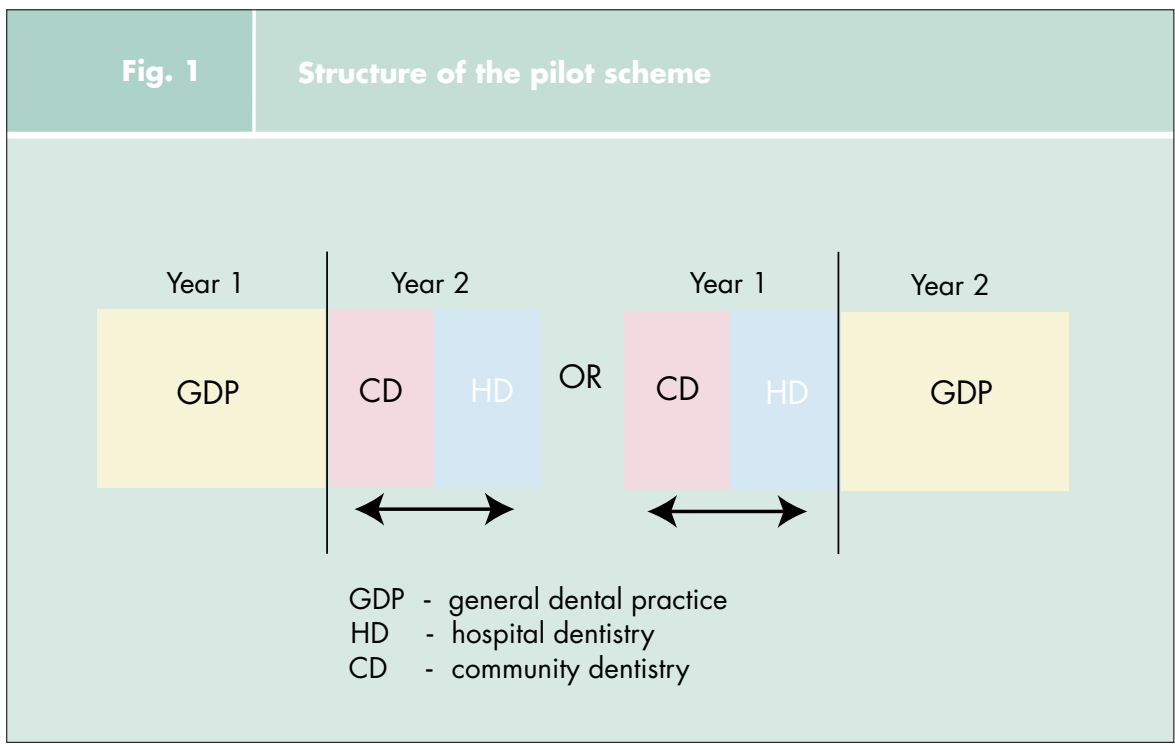

methods. Focus groups were held at regular intervals with GPTs and others throughout the evaluation to identify and discuss issues
Table Questionnaires to trainees and trainers

\begin{tabular}{|c|c|c|c|}
\hline \multicolumn{4}{|c|}{ Stage 1: Start of training questionnaire } \\
\hline & $\begin{array}{c}\text { Questionnaires } \\
\text { sent out }\end{array}$ & $\begin{array}{l}\text { Questionnaires } \\
\text { returned }\end{array}$ & $\begin{array}{l}\text { Response } \\
\text { rate }\end{array}$ \\
\hline $\begin{array}{l}\text { VDP } \\
\text { Community Trainees } \\
\text { Hospital Trainees } \\
\text { GPTs }\end{array}$ & $\begin{array}{r}74 \\
5 \\
55 \\
16\end{array}$ & $\begin{array}{r}55 \\
4 \\
26 \\
15\end{array}$ & $\begin{array}{l}74 \% \\
80 \% \\
47 \% \\
94 \% \\
\end{array}$ \\
\hline TOTAL & 150 & 100 & $67 \%$ \\
\hline \multicolumn{4}{|c|}{ Stage 2: End of training questionnaire } \\
\hline & $\begin{array}{c}\text { Questionnaires } \\
\text { sent out }\end{array}$ & $\begin{array}{l}\text { Questionnaires } \\
\text { returned }\end{array}$ & $\begin{array}{l}\text { Response } \\
\text { rate }\end{array}$ \\
\hline $\begin{array}{l}\text { VDPs } \\
\text { Vocational Trainers (GDS) } \\
\text { Community Trainees } \\
\text { Vocational Trainers (CDS) } \\
\text { Hospital Trainees } \\
\text { Consultant Trainers } \\
\text { GPTs }\end{array}$ & $\begin{array}{r}74 \\
74 \\
5 \\
6 \\
55 \\
32 \\
16\end{array}$ & $\begin{array}{r}58 \\
60 \\
4 \\
5 \\
31 \\
23 \\
16\end{array}$ & $\begin{array}{l}78 \% \\
81 \% \\
80 \% \\
83 \% \\
56 \% \\
72 \% \\
100 \%\end{array}$ \\
\hline \multicolumn{4}{|l|}{ GPT Trainers } \\
\hline $\begin{array}{ll}\text { - } & \text { GDS } \\
\text { - } & \text { HDS }\end{array}$ & $\begin{array}{c}8 \\
4 \\
\mathrm{n} / \mathrm{a}\end{array}$ & $\begin{array}{c}8 \\
3 \\
n / a\end{array}$ & $\begin{array}{l}100 \% \\
75 \% \\
\mathrm{n} / \mathrm{a}\end{array}$ \\
\hline TOTAL & 274 & 208 & $76 \%$ \\
\hline
\end{tabular}

and to track changes over time. Individual telephone interviews were conducted with all 16 GPTs and twelve trainers involved in the GPT scheme. This range of methods enabled us to elicit responses touching on many aspects of being either a trainer or a trainee and enabled them, as stakeholders in postgraduate dental education, to contribute towards the development of the pilot. Their responses are reported here in four broad but overlapping categories.

\section{Support for trainers}

The pilot scheme encouraged greater understanding of each branch of dentistry for all trainers and trainees involved but the six months' placements meant that trainers needed to maintain a higher level of input than had been previously required; as trainers' relationships with trainees were central to the scheme's success, more support should be available to them. This requires greater investment in training of trainers, meetings for GPT trainers to share their experiences, discuss problems and co-ordinate activities and, importantly, improved feedback for all trainers on their performance. Written educational contracts for all parties involved in training and the introduction of written procedures for GPTs and their trainers to follow in the event of problems with the training partnership should help to address some of the potential pitfalls. 
Trainees in the hospital dental service (HDS) identified poor quality teaching at seminars as among the least valuable aspects of training and the report recommended improved induction procedures for HO/SHOs and GPTs and more dedicated time with consultant trainers.

The six-month periods that GPTs spent in the hospital and community services had an impact on support staff, who found themselves interacting with more trainees who were new to their branch of the service, and trainers, who found that they had to dedicate more time to supporting GPTs than 'standard' trainees. Other models of GPT which offer a year in two of the three branches of dentistry on a split week basis may avoid this problem.

The demands on trainers and support staff were greater if they worked with an inexperienced GPT during his or her first placement, particularly in the HDS. It was acknowledged, however, that GPTs completing their second or third attachment were generally more competent than other new trainees and introduced new ideas and a welcome dynamic to the working environment.

\section{Support for trainees}

GPT trainees provided valuable support for one another and the provision of e-mail should be considered as a means of improving communication between trainees. Trainees from all cohorts would like more training in information technology and most trainees wanted more time for personal study or an assurance that their study time would be protected. Trainers, however, were reluctant to extend exam leave or protected study time and were less inclined than their trainees to welcome 'off the job' training such as study days and residential courses. All trainees valued study days and core days very highly, although some courses proved to be disappointing. The report recommended that there should be information about the teaching and learning methods trainees can expect to encounter and that there should be a designated organiser for GPT study days to ensure that there is an integrated programme pitched at an appropriate level.

From the trainees' perspective, the evalu- ation showed that GPTs understood the aims of training despite the more complex nature of the two-year programme. They were adequately supported in general dental practice (GDP) and in the community dental service, as were their counterparts participating in the established training programmes provided in these branches of dentistry, although greater accessibility to CDS trainers was requested.

Although vocational dental practitioners (VDPs), community trainees and GPTs had access to considerable support in their study arrangements, hospital trainees were expected to take more responsibility for their professional development. Hospital trainees would like more dedicated time with their trainers, more learner-centred training and safeguards for protected study time.

A majority of VDPs would like more opportunities to work in the different branches of the dental service although hospital and community trainees tend to have clearer career objectives and so are not as concerned about this. Trainees from all cohorts wanted more and better career guidance, suggesting that many trainees are not making fully informed decisions about their future careers.

The GPT Committee report ${ }^{6}$ stated that 'training programmes must take account of the fundamental importance of providing continuity of patient care'. The year that GPTs spent in GDP offered them good opportunities to acquire a patient list and follow through most treatment plans but continuity of patient care was more of a problem in the community and hospital services as GPTs spent only six months in each. This problem was commonly overcome in the CDS by ensuring that a dental nurse with whom the patient was already familiar was present. Maintaining continuity of care in some hospital departments was more difficult because GPTs did not have a dedicated list of patients (as they did in GDP and the CDS) and they rotated through departments, spending mornings and afternoons in different specialities.

\section{Developing Skills}

While GPTs and their trainers recognised that there were limits to what they could do during the six-month blocks in the CDS and HDS, they were very pleased with the opportunities provided to develop both their clinical and generic skills and considered that the pilot built on the strengths of the established GDP, community and hospital schemes. GPTs' expectations were surpassed in a number of areas and they had significantly more opportunities to develop a range of clinical and communication, team-work and management skills than trainees from any other of the established training schemes. Over the two-year period GPTs treated a wider range of patients than VDPs, CDS or HDS trainees and interacted with professionals from all three branches of the dental service.

Trainees and trainers expressed satisfaction with the existing one-year GDP element and considered that it should be part of any two-year GPT programme. One year in GDP provided trainees with opportunities to practise routine dentistry, helping them to improve their dexterity and speed as well as their general confidence, and to develop good time- and patient-management skills. GDP encourages trainees to identify and address their personal strengths and weaknesses and provides insight into financial and business management (although trainees wanted more), thereby helping to provide trainees with skills necessary for the transition to independent practice.

The hospital service's contributions included providing trainees with opportunities to develop clinical skills and treat oncall and trauma patients. Trainees were exposed to real-life emergency situations and had opportunities to work as part of a multidisciplinary team.

As trainees in the CDS travel to schools and residential homes in the community and were not always directly supported by their trainer they needed to have good time-management, planning and problemsolving skills. They worked closely with dental nurses, often as part of a multidisciplinary team, and developed effective teamworking skills as a result of working in different environments. Although trainees did not have opportunities to practise a wide range of advanced clinical restorative 
work, they learnt to deal with challenging patients and had more opportunities than other cohorts to practise health promotion and preventive dentistry.

The evidence indicated that GPT offers advantages over the established training schemes. With experience of the three different branches of the dental service trainees had a better understanding of the referral system from all points of view and were able to begin to break down the artificial barriers separating the different branches of the dental profession. However, there should be more emphasis on financial and business management for all trainee cohorts, and consideration should be given to providing GPTs with the option of specialising in only one area in the HDS instead of rotating through different departments.

\section{Monitoring progress: assessment and feedback}

Less formal methods of assessment, including peer review, self-assessment and informal appraisal by their trainer, were favoured by all trainees as an effective way of getting feedback on their progress and it was recommended that all trainers should receive training in appraisal and assessment. The log book or the portfolio was seen as useful for facilitating discussion between trainer and trainee and providing a record of trainees' achievements but many trainees found completing these documents an onerous task and GPTs in particular were confused by the variety of record books they were requested to keep.

Practical and clinical exams were regarded as appropriate means of assessment by HO/SHOs, whose training focuses on the attainment of the postgraduate qualifications necessary for a future career in the HDS. Although a majority of trainees from all cohorts intended to attempt a formal professional qualification at some point in the future, they wanted to decide the circumstances for themselves. It was not mandatory for GPTs to take postgraduate exams but consideration should be given to developing an appropriate qualification to mark the end of GPT.

\section{Assessing the General Professional Training pilot scheme}

An assessment of the GPT pilot scheme's success and the identification of areas for development can be formed by returning to the three main aims of the evaluation.

The advantages and disadvantages of GPT contrasted with the standard programmes

The GPTs surveyed in this study were broadly supportive of the main aims and principles of GPT with $87 \%$ believing it should include training in all three services, although a majority of trainees from all cohorts believed that GPT should remain voluntary for the foreseeable future. The majority of trainees and trainers in all branches of the dental service supported the notion that all dentists should have a common core of training in both primary and secondary care. Respondents did not believe that GPT would disadvantage any particular group either professionally or financially, but believed that it would provide trainees with financial security, more career options and it would encourage them to see education as part of their lifelong career development.

Survey results as well as interview and focus group data revealed that the GPT pilot had the following benefits:

- an improved understanding of the referral system from all points of view

- better appreciation of the work of the community dental service

- better communication between the different branches of the dental service and the breakdown of artificial barriers between primary and secondary care

- dentists with more advanced clinical skills, good generic skills, informed career options and greater adaptability.

The GPT pilot had the following drawbacks compared with the standard programmes:

- trainees found it onerous to complete the variety of record books they were requested to keep

- the six-month blocks led to some problems with continuity of patient care in the hospital and community services
- GPT trainers needed to maintain a higher level of input than was required on the established schemes and need more support. However, all trainers should receive training in appraisal and assessment.

\section{The challenges facing GPT and} recommendations for improvement Certain challenges need to be faced if GPT is to be expanded. Barriers to its success include the resource implications of inadequate levels of support for training in the hospital service and a dearth of community training posts. SCPMDE made resources available to support the core educational programme, joint trainer meetings and adviser sessions in addition to using existing vocational training and study-leave funds. However, despite a high level of commitment from members of the GPT management group, resources are required to fund a dedicated GPT coordinator for the GPT programme.

Discussions with the Steering Group revealed that GPT does not integrate well with existing contractual arrangements. Three different contracts were required for GPTs in the GDS, CDS and HDS resulting in three different salary scales. Although no problems emerged from these arrangements during the pilot scheme, there would be merit in rationalising arrangements in future by developing an integrated contractual and salary framework. Other areas which were identified as needing improvement, such as study days and log books, are more easily remedied.

\section{The level of support for the development} of GPT

Trainees and trainers from all cohort groups were asked to say whether they thought the GPT programme should include training in two or all three branches of the dental service. Incorporating the CDS in a two-year mixed programme prompted more reservations from HDS trainees than other cohorts, although more favoured this arrangement than a programme involving only the GDS and HDS. Trainees from CDS were split as to whether GPT should involve all three 
dental services or only general practice and hospital dentistry. However, GPTs who were not initially as interested in working in the community service as the other two branches reported that their experiences in the CDS had shattered previous misconceptions about the range of work undertaken. The GPTs on the pilot scheme who had experienced training in all three branches of dentistry were very supportive of continuing such an arrangement.

Some trainers and trainees expressed the opinion that it would be useful for the GDP component of a block programme to be completed first as trainees would benefit from the constant contact with GDP trainers, would have opportunities to treat a wide range of patients and would receive a good grounding in routine dentistry. The clear departure from the hospital-based undergraduate programme would mean they saw themselves as fully qualified dentists and they would gain a year's experience without interruption.

However, most trainers involved in GPT preferred the current mixed arrangement. Some consultant trainers in the hospital service favoured this approach because it allowed young house officers to work alongside GPTs with either six months' experience in the CDS or a year in GDP. The mix of talent and skills was perceived as an advantage, allowing trainees at different stages of their education with different experiences to learn from one another.

\section{Conclusions}

The majority of informants agreed that all dentists should have a common core of training in primary and secondary care and that GPTs were provided with better opportunities to develop their clinical and generic skills than trainees involved in the standard programmes.

The pilot achieved its objective of providing trainees with experience of the different branches of the dental service, helping them make informed choices and providing them with opportunities for continuing professional development, although trainees and trainers acknowledged the limitations of six-month blocks in the community and hospital services.

General Professional Training clearly aids the development of more knowledgeable and better informed dentists and the extended period of training appeared to engender a further commitment to lifelong learning and continuing professional development. Trainees felt that knowledge of all three branches of the dental service would help them to make an informed choice and the destinations of the 16 GPTs for their next year reflect the breadth of training: eight went into general practice, four took up SHO posts, two went into the community dental service, one joined the armed forces dental service, and one has combined working in the community and hospital services.

The pilot built on the strengths of the standard programmes in the general practice, community and hospital services, yet provided a programme that was greater than the sum of its parts. Despite some organisational and infrastructural problems, the GPT pilot had important benefits.

We should like to thank all trainers and trainees who participated in the evaluation. We are also indebted to Marion Devine, formerly of SCRE, for her contribution to the early stages of this study, Mr Martyn Steed and members of the General Professional Training Steering Group, and Dr Jim Rennie, Director of Postgraduate Dental Education at SCPMDE.

1 The Next Two Years - General Professional Training. Report for Consultation from the General Professional Training Committee. London: General Dental Council, August 1998.

2 Dental Strategy Review Group p.4, The Next Two Years 1981.

i) Statement on Vocational Training. GDC Education Committee. Report to the Council; May 1987, annexure 1 to Council Paper Publication no. 5.

ii) Report of Dental Review Working Party. Review of Dental Education. University Grants Committee. February 1988.

3 UK Specialist Dental Training. Report from the Chief Dental Officer. NHS Executive. May 1995.

4 Primary Care: Delivering the Future. London: Department of Health. December 1996.

5 A Bridge to the Future: an Evaluation of General Professional Training for Dentistry in Scotland. Available free of charge from Scottish Council for Postgraduate Medical and Dental Education, Hobart House, 80 Hanover Street, Edinburgh EH2 1EL (tel: 0131220 8607; fax 01312255891 , or download from http://www.scre.ac.uk/scotresearch/mussbridge/

6 The Next Two Years. op. cit. 